NBER WORKING PAPER SERIES

\title{
DOES INFLATION HARM ECONOMIC GROWTH? EVIDENCE FOR THE OECD
}

\author{
Javier Andrés \\ Ignacio Hernando
}

Working Paper 6062

\author{
NATIONAL BUREAU OF ECONOMIC RESEARCH \\ 1050 Massachusetts Avenue \\ Cambridge, MA 02138 \\ June 1997
}

Presented at the NBER conference on "The Costs and Benefits of Achieving Price Stability," Federal Reserve Bank of New York (February 20-21, 1997). We are grateful to Palle Andersen, Sean Craig, Juanjo Dolado, Rafael Doménech, Angel Estrada, Frederic Mishkin, Teresa Sastre, Javier Vallés, José Viñals and the participants at the conference for their comments and to Francisco de Castro for his excellent research assistance. Javier Andrés acknowledges the financial support by DGICYT grant SEC96-1435-C03-01. This paper is part of NBER's research program in Monetary Economics. Any opinions expressed are those of the authors and not those of the National Bureau of Economic Research.

C 1997 by Javier Andrés and Ignacio Hernando. All rights reserved. Short sections of text, not to exceed two paragraphs, may be quoted without explicit permission provided that full credit, including $\mathbb{C}$ notice, is given to the source. 
Does Inflation Harm Economic Growth?

Evidence for the OECD

Javier Andrés and Ignacio Hernando

NBER Working Paper No. 6062

June 1997

JEL Nos. E31, F43, O49

Monetary Economics

\begin{abstract}
The purpose of this paper is to study the correlation among growth and inflation at the OECD level, within the framework of the so-called convergence equations, and to discuss whether this correlation withstands a number of improvements in the empirical models, which try to address the most common criticisms of this evidence. The main findings are the following: 1) the negative correlation among growth and inflation is not explained by the experience of high-inflation economies; 2) the estimated costs of inflation are still significant once country-specific effects are allowed for in the empirical model; and 3) the observed correlation cannot be dismissed on the grounds of reverse causation (from GDP to inflation).
\end{abstract}

Javier Andrés

Campus dels Tarongers

Av. dels Tarongers, $s / n$

Edifici Departamental Oriental

Universitat de València

46011 València

SPAIN

Javier.Andres@uv.es
Ignacio Hernando

Banco de España

Alcalá, 50

28014 Madrid

SPAIN

hernando@bde.es 


\section{Introduction.}

From 1973 until 1984 OECD economies underwent a period of macroeconomic distress in which inflation escalated to reach an average rate of $13 \%$, three times as high as in the previous decade. Since then, achieving a low and stable inflation has become the main goal of monetary policies in western economies. This move in monetary policy-making rests on the belief, firmly rooted in many economists and politicians' minds, that the costs of inflation are non-negligible, so that keeping inflation under control pays off in terms of faster sustainable growth in the future.

The shortage of theoretical models explicitly addressing the issue of the longrun effects of inflation has not prevented many researchers from trying to estimate the costs of inflation. A series of recent papers have tried to assess the long run impact of current inflation within the framework of the so called convergence equations. These equations can be derived from a theoretical model of economic growth and, although the precise channels through which inflation affects growth are not always made explicit, they represent several advantages for the purposes at hand. First, and foremost, an explicit model reduces the risk of omitting relevant variables. Second, convergence equations allow for a variety of effects of inflation, including those which reduce accumulation rates and those which undermine the efficiency with which productive factors operate. Finally, in this framework a clear distinction can be made between level and rate of growth effects of inflation; this difference matters as regards the size and the timing of the costs of inflation. This paper sticks to this methodology, whose main shortcoming is that it focuses on long run issues, disregarding the short run costs associated to disinflation (the sacrifice ratio). Our purpose is to study the correlation among growth and inflation at the OECD level and to discuss whether this correlation withstands a number of improvements in the empirical models, which try to address the most common criticisms on this evidence. In particular, we aim to answer the following questions: is this correlation explained by the experience of high-inflation economies?; are the estimated costs of inflation still significant once country-specific effects are allowed for in the empirical model?; 
can the observed negative correlation be dismissed on the grounds of reverse causation (from GDP to inflation)?.

The rest of the paper is organized as follows. Section II briefly summarizes the literature dealing with the costs of inflation, the empirical model and the data used. In section III we present the estimated convergence equations augmented with the rate of inflation, whereas in section IV the empirical model is further augmented to allow for cross-country heterogeneity. In these two sections, we test the sensitivity of the results to the exclusion of high-inflation countries. In section IV we estimate the long run benefits of a permanent disinflation and address the issue of whether the cost of inflation varies with the level of inflation or not. In section $V$ standard causality tests are applied to the inflation-growth relationship. Section VI concludes with some additional remarks. The main results of the paper can be summarized as follows. Even low or moderate inflation rates (as the ones we have witnessed within the $O E C D$ ) have a negative temporary impact upon long-term growth rates; this effect is significant and generates a permanent reduction in the level of per capita income. Inflation not only reduces the level of investment but also the efficiency with which productive factors are used. The estimated benefit of a permanent reduction in the inflation rate by a percentage point is an increase in the steady-state level of per capita income which ranges from $0.5 \%$ to $2 \%$. Although the size varies somewhat across specifications (as well as across different levels of inflation), the correlation among inflation and future income is never found positive. This result holds across different sub-samples (even excluding high-inflation countries) and is also robust to alternative econometric specifications. In particular, inflation Grangercauses income and the current and lagged correlation between these two variables remains significant when we control for country-specific variables (such as the accumulation rates) and time invariant effects. 


\section{The theoretical framework.}

\section{II.1 International evidence.}

The negative effects of inflation have been studied in the context of the models of economic growth ${ }^{1}$, in which the continuous increase of per capita income is the outcome of capital accumulation along with technological progress. The uncertainty associated to a high and volatile unanticipated inflation has been found to be one of the main determinants of the rate of return of capital and investment (Bruno (1993), Pindyck and Solimano (1993)). But even fully anticipated inflation may reduce the rate of return of capital given the non-neutralities built into most industrialized countries' tax systems (Jones and Manuelli (1993), Feldstein (1996)). Besides, inflation undermines the confidence of domestic and foreign investors about the future course of monetary policy. Inflation also affects the accumulation of other determinants of growth such as human capital or investment in $R+D$; this channel of influence is known as the accumulation or investment effect of inflation on growth.

But, over and above these effects, inflation also worsens the long-run macroeconomic performance of market economies by reducing total factor productivity. This channel, also known as the efficiency channel, is harder to formalize in a theoretical model ${ }^{2}$, nonetheless its importance in the transmission mechanism from inflation towards lower growth cannot be denied. A high level of inflation induces a frequent change in prices which may be costly for firms (menu costs) and reduces the optimal level of cash holdings by consumers (shoe-leather costs). It also generates larger forecast errors by distorting the information contents of prices, encouraging economic agents to spend more time and resources in gathering information and protecting themselves against the damages caused by price

${ }^{1}$ See Orphanides and Solow (1990), De Gregorio (1993), Roubini and Sala-iMartín (1995) amongst others.

${ }^{2}$ Briault (1995) surveys the literature on these effects. 
instability, hence endangering the efficient allocation of resources. Although some theoretical models analyze the components of the efficiency channel in more detail, it is difficult to discriminate among them in aggregate empirical growth equations. Thus, we shall not pursue this issue further here and we shall turn our attention to the empirical evidence.

Several authors have found a negative correlation between growth and inflation. Kormendi and Meguire (1985) estimate a growth equation with crosssection data and find that the effect of inflation on the growth rate is negative, although it loses explanatory power when the rate of investment is also ircluded in the regression. This would indicate that the effect of inflation mainly manifests itself in a reduction in investment but not in the productivity of capital. Grier and Tullock (1989) estimate a model that excludes the rate of investment and includes several measures of nominal instability (such as the inflation rate, the acceleration of prices and the standard deviation of inflation). The results differ according to the group of countries considered, but for the OECD only the variability of inflation seems to have a significant and negative effect on growth.

More recently, the study of the long-run influence of inflation has progressed within the framework of convergence equations developed by Barro and Sala-iMartín $(1991)^{3}$. Fischer $(1991,1993)$ reports a significant influence of several shortterm macroeconomic indicators, and in particular inflation, on the growth rate. Cozier and Selody (1992) estimate cross-section convergence equations for different samples and find a fairly large negative effect of inflation on income at the OECD level. These authors conclude that inflation affects the level rather than the growth rate of

${ }^{3}$ Several exceptions, however, are worth noting: the studies of Grimes (1991) for the OECD, Smyth (1994) for the United States, Cardoso and Fishlow (1989) who use a panel of five-year averages for 18 Latin American countries, and Burdekin, Goodwin, Salamun and Willett (1994) and Bruno (1993). In all these studies, a significant negative effect of inflation on growth is reported. On the other hand, Bullard and Keating (1995) find that the long-run output response to permanent inflation shocks in a SVAR model is zero, for most advanced economies. 
productivity and that the impact of inflation variability is weak ${ }^{4}$. This finding coincides with the result obtained more recently by Barro $(1995,1996)$ in a sample of 120 countries, who reports a negative long-run effect of inflation using alternative instruments to correct for the endogeneity of inflation. The general conclusion of these and other studies (De Gregorio (1992a, 1992b and 1996), Motley (1994)) is consistent with the negative correlation between inflation and income in the long run suggested in the theoretical literature. However, the consensus in this respect is far from absolute, and several authors have criticised these findings, arguing that the lack of a fully developed theoretical framework makes it difficult to interpret the empirical correlations and that even these are not robust to changes in the econometric specification. The latter argument is developed by Levine and Renelt (1992), Levine and Zervos (1993) and Clark (1993). Levine and Renelt carry out an exhaustive sensitivity analysis among broad set of regressors in growth equations and conclude that the statistical significance (and even the sign) of most of these variables (inflation among them) is not invariant to changes in the information set ${ }^{5}$. Nor do these results, in turn, escape criticism. Sala-i-Martín (1994) argues that the problem of finding a macroeconomic variable whose effect is invariant to alternative specifications of the convergence equation should not be taken to mean that this influence is absent, but should instead be viewed as a sign of the difficulty of finding indicators that can adequately capture this effect for any period and group of countries. Gylfasson and Herbertsson (1996) find that the inflation rate is robust to changes in the conditioning set, whereas Andrés, Doménech and Molinas (1996) show that, for the OECD as a whole, short run macroeconomic variables are as robust (if not more) as the rates of accumulation in explaining economic growth and that this holds for alternative conditioning sets as well as across different time periods.

${ }^{4}$ Judson and Orphanides (1996) measure the variability of inflation as the variance of the quarterly rate for each country and find that it is negatively correlated with growth. These authors also find a significant negative effect of the level of inflation. They use annual data and do not include initial GDP among the regressors.

${ }^{5}$ McCandless and Weber (1995) conclude also that the cross-country correlation among inflation and growth is zero. 


\section{II.2. The effect of inflation in convergence equations.}

There are a number of advantages in approaching the correlation between inflation and growth within the framework of the convergence equations as proposed by Barro and Sala-i-Martín (1991), which represent the main empirical proposition of growth models with constant returns ${ }^{6}$. In this paper we do not intend to test any particular model of economic growth, nor the use of the convergence equation means that the exogenous growth model is the only possible representation of the evolution of OECD economies in the long run. As Gylfason and Herbertsson (1996) have pointed out, this equation might encompass the empirical implications of many endogenous growth models. The main advantage of this specification is that it systematically captures most of the factors that have been usually considered as determinants of growth, reducing the risk of omitting relevant regressors entailed in ad hoc specifications ${ }^{7}$. The technology is represented by the following production function of constant returns (Mankiw, Romer and Weil, 1992),

$$
Y_{t}=\left(A_{t} L_{t}\right)^{\beta} K_{t}^{\alpha} H_{t}^{\gamma}
$$

Total factor productivity $\left(A_{1}\right)$ grows at the constant exogenous rate $\phi$, whereas fixed capital $(\mathrm{K})$ and human capital $(\mathrm{H})$ grow in proportion to the output assigned for their accumulation ${ }^{8}$. Assuming that the depreciation rates of both factors are the same, it is possible to derive the following equation of growth between two moments in time:

${ }^{6}$ De Gregorio (1993) and Roubini and Sala-i-Martín (1995) provide more elaborate models of the interaction between inflation and growth.

${ }^{7}$ In particular, unlike those equations that do not include the catching-up component, the convergence equation provides a way of controlling the level of per capita income when analysing the determinants of its growth rate. This turns out to be of crucial importance to obtain a significant correlation between growth and inflation.

${ }^{8}$ In the original formulation of Solow (1956), the rate of technological progress is exogenous, although in more recent models it can be explained by the set of resources assigned to research, market size, learning-by-doing, etc. 


$$
y_{T+\tau}-y_{T}=\phi \tau+\left(1-e^{-\lambda \tau}\right)\left[\Omega^{c}+y_{T}^{*}-y_{T}\right]
$$

where $y$ represents the logarithm of per capita income in the period indicated by the subscript, and $y^{*}$ represents its steady-state value. Expression [2] indicates that the growth rate of an economy will have a component determined by the growth in factor productivity, $\phi$, and another resulting from the economy's propensity to move to its steady-state level if, for some reason (shocks, initial conditions, etc.), it lies outside. $\lambda$ is the rate at which the economy closes the gap between its current income and its potential or steady-state level ${ }^{9}$. This level is, in turn, determined by the parameters of the production function and by the rates of accumulation of the productive factors:

$$
y_{T}^{*}=\Omega^{s}+\phi T+\beta^{-1}\left[\alpha s_{T k}^{*}+\gamma s_{T h}^{*}-(\alpha+\gamma) \log \left(n_{T}^{*}+\phi+\delta\right)\right]
$$

where $s_{k}^{*}$ is the logarithm of the rate of investment, $s_{h}^{*}$ represents the logarithm of the rate of accumulation of human capital, and $n^{*}$ is the growth rate of the population, all evaluated at their steady-state level; $\delta$ is the depreciation rate of capital which will be assumed equal to $3 \%$, while the two constants combine different parameters of the model and the starting level of technology $\left(\mathrm{A}_{\mathrm{T}}\right)$.

This structure allows us to test the different hypotheses considered in this paper. First, the presence of the rates of factor accumulation in [3] is useful to discriminate between the two channels through which macroeconomic imbalances can affect the growth rate. Thus, if inflation reduces total factor productivity, we could expect a significant coefficient of the rate of inflation in equation [5]. In this case, the productivity index $\left(\mathrm{A}_{\boldsymbol{t}}\right)$ might be assumed to evolve as in [4] (Cozier and Selody (1992)), which reflects the influence of the inflation rate $(\pi)$ and its variability $(\sigma)$ :

${ }^{9}$ This rate can be written as: $\lambda=(1-\alpha-\gamma)\left(n^{*}+\phi+\delta\right)$. 


$$
A_{t}=A_{0} \exp (\phi t) \exp \left(\mu_{1} \pi_{t}\right) \exp \left(\mu_{2} \sigma_{t}\right)
$$

The empirical specification is then given by:

$$
\begin{gathered}
y_{T+\tau}-y_{T}=\phi \tau+\left(1-e^{-\lambda \tau}\right) \\
{\left[\Omega-y_{T}+\phi T+\mu_{1} \pi_{T}+\mu_{2} \sigma_{T}+\beta^{-1}\left(\alpha s_{T k}^{*}+\gamma s_{T h}^{*}-(\alpha+\gamma) \log \left(n_{T}^{*}+\phi+\delta\right)\right)\right]}
\end{gathered}
$$

However, if inflation influenced growth solely through its impact on investment $\left(\mathrm{s}_{\mathrm{k}}\right)$, its coefficient in [5] would not be significant ${ }^{10}$. Unless when it is necessary we shall not impose the parametric restrictions in the previous equations and we shall focus in the linear version [5'] instead,

$$
y_{T+\tau}-y_{T}=\Psi_{0}+\psi_{1} T+\Psi_{2} y_{T}+\Psi_{3} s_{T K}^{*}+\Psi_{4} s_{T H}^{*}+\psi_{5} \log \left(n_{T}^{*}+\phi+\delta\right)+\Psi_{6} \pi_{T}+\psi_{7} \sigma_{T}
$$

Second, the exogenous growth model specifies the determinants of both the long-run level of per capita income and of the sustained growth rate. Inflation can affect one and/or the other, although the implications in terms of welfare are different ${ }^{11}$. According to the specification of equation [4], the impact of inflation basically impinges on the potential level of income, but not on sustained growth (represented by $\phi$ ). To examine the latter possibility, we shall also consider an alternative specification, [4'], which allows for the influence of inflation on the long-run growth rate ${ }^{12}$ :

$$
A_{t}=A_{0} \exp \left[\left(\phi+\phi^{\prime} \pi\right) t\right] \exp \left[\mu_{1} \pi\right]
$$

such that the equation to be estimated would be represented by:

${ }^{10}$ In this case, the impact of inflation on growth in the long run should be evaluated by estimating investment equations.

${ }^{11}$ See Thornthon (1996) for a discussion of this issue.

12 This is the specification proposed by Motley (1994). The variability of inflation is excluded in order to simplify the expression. 


$$
\begin{gathered}
y_{T+\tau}-y_{T}=\left(\phi+\phi^{\prime} \pi\right) \tau+\left(1-e^{-\lambda \tau}\right) \\
{\left[\Omega-y_{T}+\left(\phi+\phi^{\prime} \pi\right) T+\mu_{1} \pi_{T}+\beta^{-1}\left(\alpha s_{T k}^{*}+\gamma s_{T h}^{*}-(\alpha+\gamma) \log \left(n_{T}^{*}+\phi+\delta\right)\right)\right]}
\end{gathered}
$$

In the next section we estimate the elasticity of growth with respect to inflation in models [5], [5'] and [6].

Our observations are four-year averages of OECD annual variables. Our data set is described at length in Dabán, Doménech and Molinas (1996) who use OECD 1990 purchasing power parities to homogenize OECD National Accounts from 1960 to 1992 . When making real income comparisons among a set of countries, we must be aware of the properties of the data elaborated for that purpose. In particular, the more transitive we want our comparisons to be, the more the reference basket of goods has to depart from the most representative sample of items for each country. Since we restrict the analysis to the OECD, we avoid the use of data sets designed to homogenize information from a much larger set of countries (as the one in the Penn World Table Mark 5, PWT 5, (Summers and Heston, 1991)).

\section{Estimation of the effect of inflation.}

Tables 1 and 2 show the instrumental variables estimates of the steady-state and the convergence equations, using one and two-periods-lagged regressors as instruments. The results are quite robust, both in the linear and in the non-linear specifications, as regards the effect of inflation. Linear models (equation [5']) are shown in Table 1. The models in columns 1 and 2 of Table 1 correspond to different versions of the convergence equation. As predicted by the neoclassical model, the parameter of initial per capita income is negative and highly significant, both when steady-state variables are included (conditional convergence) and when they are not (unconditional convergence). In column 2, the coefficients of the input accumulation rates have the expected sign, although the one for human capital is non-significant. The estimated parameter of the trend, which according to the theoretical model is 
approximating the rate of technological progress, has an unexpected negative $\operatorname{sign}^{13}$. On the other hand, the trend coefficient has the expected positive sign in the steadystate equation (columns 3 and 4), but the values of the coefficients of the accumulation rates suggest a far too large share of human capital in the production function.

When the inflation rate and its variability (proxied by the Pearson coefficient) are included, the rest of the parameters do not change significantly. The coefficient of the inflation rate is negative and significant, both in the convergence and in the steady-state equation, whereas no significant effect is found from the variability of inflation. Thus, the equations presented hereafter exclude this variable. When the factor accumulation rates are included (columns 2 and 4 ) the size of the inflation effect is smaller than when they are omitted (columns 1 and 3), but it is still significant. These results suggest that there are two channels by which inflation influences growth: first, through a reduction in the propensity to invest, and second, through a reduction in the efficiency in the use of inputs.

Non-linear models (equation [5]) are shown in Table 2. The estimated parameters of the accumulation rates in the steady-state equation (column 1) are quite far from the usually obtained in the empirical literature, the low value of $\alpha$ being particularly remarkable. The effect of inflation is negative and significant. The estimated coefficients in the convergence equation (column 2) look more reasonable, pointing towards a technology of similar factor shares $(\{1 / 3,1 / 3 / 1 / 3\})$, with an implicit rate of convergence around $2.7 \%$. Again, the effect of inflation is negative and significant.

${ }^{13}$ A possible interpretation for this result is that the trend may be capturing the process of sustained reduction in the rate of growth of per capita income suffered by OECD countries during part of the sample period. We have tried alternative characterizations of technological progress: first, including time dummies instead of the linear trend and, second, imposing a rate of technological progress of $2 \%$. The estimated coefficients, including that of inflation, do not change significantly. These results are not reported to save space. 
Additionally, some tests of the sensitivity of the inflation coefficient to the sample definition have been performed, in order to ascertain if the negative correlation among inflation and income is driven by the presence of some highinflation countries. The most noticeable change in the estimated coefficient takes place when Iceland is excluded from the sample. In such case (column 3 of Table 2) the correlation among inflation and growth is almost twice as high as when it is included. This is not surprising since Iceland being the country with the second highest average inflation within the $\mathrm{OECD}$, is also a high-income fast-growth economy which may be generating a downwards bias (in the absolute value of) the growth-inflation correlation. We have proceeded to estimate the model for different sub-samples, according to their average inflation. The results, depicted in Chart 1 , indicate that, if anything, the coefficient of inflation in the convergence equation is higher (in absolute value) and more significant for low-inflation countries.

The negative effect of inflation on per capita income seems to be robust both in the steady-state and in the convergence equation. Although the negative influence of inflation on per capita income is well established, the effect on the sustainable growth rate is less clear. If the inflation rate is a determinant of steady-state per capita income $\left(\mathrm{y}^{*}\right)$ it should also appear in the convergence equation. But it is not clear whether the negative coefficient in this equation points to an effect on the level or on the growth rate of output. To discriminate between these effects we have estimated equation [6], allowing for an effect of inflation both on the steady-state level of income $(\mu)$ and on the permanent component of the growth rate $\left(\phi^{\prime}\right)$. Both these coefficients are negative and significant when they are introduced individually, but when they are jointly included in the model (column 4) the effect on the trend component takes an unexpected positive sign. This would indicate that the negative effect of inflation impinges upon the level of per capita income but not on the sustainable rate of growth of the economy. Thus, the impact on the growth rate is transitory (in the medium run), as long as convergence is under way.

Summing up, the analysis in this section, in accordance with other studies, supports the evidence of an adverse influence of inflation on growth. As regards the 
size of this effect, if we take the coefficient in column 3 of Table 2 as a reliable estimate of the long-run effect of inflation upon growth, an increase in average inflation by one percentage point reduces per capita growth by 0.08 points per year. This fall in the growth rate is not permanent but it lasts for a long period leading to a permanent reduction in steady-state per capita income of $2.5 \%{ }^{14}$. However, before to draw any policy implication out of these figures it is convenient to take a closer look at the relationship between inflation and growth, trying to correct for some biases that might arise in specifications like the ones studied so far.

\section{Country-specific effects and the cost of inflation.}

There are several reasons to include individual effects in convergence equations estimated with multi-country data sets. Most empirical analyses of economic growth have relied on the use of information for wide groups of countries. This makes possible to focus on the low-frequency properties of the data, taking time series averages and still avoiding a severe shortage of degrees of freedom. However, this approach imposes a very strong restriction, namely that the data for all the economies of the sample stem from the same theoretical distribution, i.e. the technological parameters are homogeneous across countries. This assumption is seldom explicitly tested, although its empirical implications may be very important ${ }^{15}$. The existence of technological differences in the rates of technical progress or, as it is more likely, in the initial conditions of each country, would lead to the presence of idiosyncratic effects in growth equations. If these and other country time-invariant characteristics affect the growth-inflation relationship, it would render the lagged regressors inappropriate as instruments in growth equations (Barro (1996)). The consideration of individual effects in the constant term (Knight, Loayza

${ }^{14}$ When Iceland is included in the sample, these figures are 0.03 and $1,1 \%$ respectively.

${ }^{15}$ See Pesaran and Smith (1995). 
and Villanueva (1993), Islam (1995)) or in a more general way (Andrés, Boscá and Doménech (1996)) might then alter significantly some of the main results of the empirical growth literature.

In this section, we test whether the estimated negative effect of inflation on growth is biased due to the omission of these country-specific (time-invariant) effects. The main results are summarized in Table 3. In column (1), the linear model (equation [ $\left.5^{\prime}\right]$ ) has been estimated under the assumption that the omitted individual effects are not correlated with the regressors. The random effects estimates, and in particular the coefficient of the inflation rate, resemble very much those of the basic model depicted in column (2) of Table 1. Nevertheless, the reasons to include country-specific effects in the model suggest that the assumption of non correlation among these and the regressors might not be appropriate in this setting. Thus, in what follows we focus on the fixed effect estimates, which we compute including dummies in the linear convergence equation. All the models have been estimated by instrumental variables. When we add a dummy variable for each country (column 2) the explanatory power of most regressors changes, as compared with the models in the previous section. In particular, while inflation still has a negative effect on income its t-statistic is now lower $(-1.16)^{16}$. The changes in the rest of the model are far more radical though. Firstly, whereas the negative trend coefficient was an unappealing feature of the models in section III, this coefficient now becomes positive and significant, with a reasonable point estimate of 0.03 . Secondly, the point estimates of the technological coefficients are now either non-significant or wrongly signed. In fact, excluding the accumulation rates from the equations, the negative correlation between growth and inflation becomes highly significant with a t-statistic of -2.29 (column 3). Finally, several country dummies are not different from zero, which means that the model might be overparametrized.

${ }^{16}$ It must be noticed that the fixed effect estimate of the coefficient of inflation is still significant at the $5 \%$ level, if we focus in the low inflation countries (LI). This coefficient is lower and weakly significant for the sub-sample of all countries but Iceland (HI-ICL) with inflation above the OECD average. 
The search for a more parsimonious specification proceeds along the following steps. Starting from the model with a dummy variable for each country, the non-significant dummy variables have been removed, setting aside the one with the lowest t-statistic each time. As a second step, these excluded variables have been added again, one at a time, retaining those with a t-ratio greater than $1.5^{17}$. Every time a dummy variable is added back into the model, the process is reinitiated. This procedure does not involve the analysis of every single possible specification according to all the combinations of country-specific constants. However, it provides a model selection procedure that allows us to test, at least twice, the marginal significance of each dummy variable: first, against a more general model (with all the country-specific dummies) and next against a more restricted one. The model in column 4 summarizes the final outcome of this specification process. The results do not change very much with respect to those in column 1 , except in that now the coefficient of the inflation rate is negative and significant and its size is similar to that obtained for the model without individual effects. Furthermore, this result is quite robust to the set of country-specific dummies included in the regression. The same search process has been also carried out for different sub-samples with different average inflation rates. The point estimates of the inflation coefficient, along with its confidence interval, are depicted in Chart 2. The coefficient of inflation turns out to be larger and more significant whenever high inflation countries are not considered. Hence, as it was the case in models without country dummies, the estimated correlation between inflation and growth (or income) does not depend on the presence of a group of high inflation countries in the sample.

Taking column 4 as a starting point, in the model in column 5 individual dummies are clustered into country-group dummy variables. The t-statistic of the

${ }^{17}$ If the threshold level of the t-ratio is 2.0 , the final specification is more parsimonious. Nevertheless, the estimated long run coefficient of inflation does not depart very much from that in column 4. 
inflation rate increases again (up to -3.99 ) ${ }^{18}$. It is quite remarkable that the negative and highly significant influence of inflation on growth during rather long periods survives all these changes in the specification. In fact, it turns out to be, along with the initial per capita GDP, the most robust variable of the model. The country groups in column 5 have been defined according to the size of the individual effect. Greece shows an individual effect that is clearly negative $(-0.31)$ as compared with the excluded countries ${ }^{19}$, followed by Turkey (-0.29), Ireland and Portugal (-0.22), Spain (-0.15), New Zealand, Finland and the United Kingdom (-0.05). On the other hand, Canada and Germany (0.04), Iceland (0.08) and Switzerland, Luxembourg and the United States $(0.1)$ display a positive individual effect on the growth rate. The estimated individual effects reveal a systematic pattern which, if ignored, could have led to a bias in the estimated effect of inflation. The individual effect is strongly correlated with the level of per capita income achieved at the end of the sample period. Thus, omitting the individual effect, the model would underestimate the growth of the richest countries overestimating that of the poorest countries. Since there is a negative correlation, at the OECD level, between per capita income in 1993 and the average inflation rate, excluding the individual effects is a source of potential upwards bias in the estimation of the effect of inflation. Indeed, although the estimated coefficient of inflation remains largely unchanged, as compared with that in Table 1, there is, nevertheless a significant change in the point estimate of the long-run effect of inflation once country-specific dummies are included in the model. The coefficient of initial GDP is now almost five times as large as the one in Tables 1 and 2, thus the estimated long-run cost of inflation is now lower. A permanent increase in one percentage point leads to a $0.75 \%$ permanent fall in output. This time though the transition period is much shorter since a higher coefficient of initial GDP means that convergence to the steady-state is much faster too.

${ }^{18}$ As in column 2, the coefficients for the input accumulation rates are not significant. The exclusion of these variables does not worsen substantially the fit of the equation and further increases the significance level of the inflation rate.

19 Australia, Austria, Belgium, Denmark, France, Netherlands, Italy, Japan, Norway and Sweden. 
Although OECD economies share certain common institutional features, their inflation performances are rather different. Once we have a more accurate estimate of the long-run cost of inflation we can address the issue of whether this cost varies according to the level of inflation or not. The different perspectives adopted to analyze the linearity of the inflation effect have led to contradictory results. For instance, Barro (1995), estimating different coefficients for different levels of inflation, finds a greater effect of inflation on growth the greater the inflation level ${ }^{20}$. Motley (1994), estimating the growth model for different sub-samples, concludes the opposite. We have tried these two approaches in equation [5'] and found that they also yield somewhat different results for the OECD, although the coefficients of inflation in different sub-samples where not very precisely estimated. In general, though, the coefficient corresponding to lower inflation rates tends to be higher although with a lower $t$ ratio. This would indicate that the benefits of lower inflation are indeed higher at low rates, although the functional form might be inappropriate to capture this result. As an alternative, we have estimated the basic model allowing for a nonlinear effect of inflation on growth. Including $\pi$ and $\pi^{2}$ both coefficients are significant while the positive coefficient on $\pi^{2}$ indicates that the marginal cost of inflation is positive but decreasing with its level. Two alternative specifications which allow for a falling marginal cost of inflation have also been tried. In these, inflation is represented by $\log (\pi)$ and the $\operatorname{ratio}^{21}(\pi /(1+\pi))$, respectively. In all the specifications tried (with country dummies, excluding Iceland, and so on) these equations perform better than the ones with the level of inflation.

A further test for linearity has been carried out in the model in $\log (\pi)$. In part A of Table 4, a different coefficient is allowed for $\log (\pi)$ depending on its level. These elasticities are always negative and significant but not statistically different. As an alternative approach, the homogeneity assumption may be relaxed by estimating the convergence equation for different sub-samples. This approach allows all the parameters, and not only the coefficient of inflation, to vary across sub-

${ }^{20}$ Although the null of linearity cannot be rejected (see also Barro (1996)).

${ }^{21}$ Gylfason and Herbertsson (1996) propose this nonlinear transformation. 
samples. The results are summarized in part B of Table 4. The effect of inflation is negative and significant both for low (and very low) as well as for high (and very high) inflation countries and the coefficient of $\log (\pi)$ is similar across different subsample specifications ${ }^{22}$. The results of these two approaches lead us to conclude that the elasticity of income with respect to inflation does not change significantly with the level of inflation. If anything, this tells us that it pays more in the case of a low-inflation country than in a high-inflation one to reduce the inflation rate by a given amount. By the same token, it is more costly for a low-inflation country to concede an additional (and permanent) point of inflation than it is for a country with a higher starting rate $^{23}$.

Table 5 shows the long-run impact upon income of a one percentage point permanent reduction of inflation for a variety of specifications of the effect of inflation. All models include country-specific constants and we report results for the OECD as a whole and also excluding Iceland. The estimated long-run benefit of a reduction of inflation from $20 \%$ to $19 \%$ varies from $0.30 \%$ to $0.75 \%$, with an average value of $0.5 \%$. At lower inflation levels (from $4 \%$ to $3 \%$ ), the benefit of the same reduction in inflation is higher, with an average $1 \%$ increase in steady-state

${ }^{22}$ The coefficient of initial GDP is also similar across the specifications in Table $4 \mathrm{~B}$. Thus, the hypothesis of homogeneity in the long-run elasticity cannot be rejected either.

${ }^{23}$ The exercises on Table 4 have been carried out for different inflation regimes and also for different specifications of the equation and the inflation term. The overall picture that comes out of these exercises is the same. The coefficient of the inflation term is negative in most cases and it tends to be bigger (in absolute value) at low inflation rates, although with lower t-statistics as well. In a few specifications the coefficient for very low inflation rates (below 3-4\%) is positive, although never significant. This issue deserves a more careful scrutiny, since it might well be that inflation ceases to be costly at all at very low levels. Since we have very few data points with inflation under 3\% in our sample, we have not been able to pursue this further. Sarel (1995) concludes that the cut-off point might be at an $8 \%$ rate of inflation. However, both the model and the data used differ from ours in several respects. 
income. These estimated values are all rather similar except for the specification in logs which overrates the benefits of disinflation at low inflation levels.

These benefits seem lower than others reported in the literature, but it must be noticed that they are obtained in equations displaying higher than usual 2-3\% convergence rate. This is most important since it means that the transition period until the increase in GDP actually takes place is shorter; thus, it would not take the representative economy much time to reap the full benefits of a sustained disinflation. In Table 6 we compare the cost of inflation estimated in the basic model (column 3, Table 2) with the one obtained in the model with country specific effects (column 4, Table 3). The estimated benefit from a permanent reduction in the inflation rate by one percentage point is higher in the former $(2.5 \%$ versus $0.75 \%)$. Nevertheless, since this is a steady-state effect and the convergence rates also differ across models $(2.5 \%$ versus $13 \%)$, the relevant comparison should be made in present value terms, which makes the outcome dependent on the discount rate. According to the figures in this example, for discount rates slightly above $4 \%$ the benefit of disinflation is larger in models with faster dynamics, despite the lower coefficient of the inflation rate in the convergence equation. Hence, the present value of the per capita income gain might well be within the range of those found in other studies.

\section{Analysis of causality.}

The models studied in previous sections can generate a non negligible bias in the estimation of the influence of inflation on growth by focusing on the contemporaneous correlation between these two variables. Inflation and growth are the joint outcome of the way in which an economy responds to different shocks. If demand shocks predominate, a positive association between GDP growth and inflation can be expected, whereas the association will be negative in response to supply shocks. Also, even if we consider the possibility of a true influence of one variable over the other, the theoretical literature presents arguments in favour of 
causality in both directions. For this reason, the contemporaneous correlation between growth and inflation may not be very informative as to the existence and magnitude of a real cost associated with inflation.

In fact, it might be the case that the estimated negative correlation between inflation and growth is driven by the predominance of negative supply shocks during the sample period. To test this possibility we have estimated the linear version of the convergence equation for two periods: a first one (1961-1972 and 1989-1992), where demand shocks predominated, and a second one (1973-1988), where supply shocks have been probably more significant ${ }^{24}$. The results of this split are shown in Table 7 , where we present only the coefficient on inflation for both the OLS and the IV estimation. As expected, the IV coefficient is higher (lower), in absolute value, than the OLS coefficient for the first (second) period given the nature of the expected bias in each case. But in all cases, the coefficients are negative and significant, meaning that the negative supply shocks that hit the OECD economies during most of the second half of the sample period are not primarily responsible for the estimated negative correlation association between inflation and growth. If this had been the case, we ought to find a positive coefficient for the first period, at least in the OLS estimation. The finding of negative coefficients for both periods strengthens the view that there is indeed a genuine negative effect of inflation upon growth that does not rely on the existence of supply shocks determining simultaneously inflation and growth.

In order to pursue this issue more thoroughly, this section analyses the statistical causality, as formulated by Granger, of inflation to growth and vice-versa. This perspective is broader than that of convergence equations in several ways. First, the analysis of causality focuses on the study of non-contemporaneous effects of one variable on the other. This is precisely the influence of inflation on growth predicted by the theoretical models: an influence that does not operate in the short run but that

${ }^{24}$ Similar results were obtained when we split the period up in other two parts: 1961-1976, for demand shocks predominance, and 1977-1992, for supply shocks predominance. 
takes time to show instead. Second, in using a more flexible specification, we avoid the imposition of the parametric restrictions of the neo-classical growth model which might make the correlation that concerns us here less clear. The analysis of causality carried out in this section does not put theoretical growth models aside. Economic theory suggests a series of growth determinants that can be incorporated into the information set in the tests of causality.

To analyse the causality from the rate of inflation to the level of per capita income ${ }^{25}$, a test is run on the joint significance of $\left\{\mathbf{d}_{1}, \ldots \mathbf{d}_{\mathrm{p}}\right\}$ in the model:

$$
y_{t}=A+C(L) y_{t}+D(L) \pi_{t}+G(L) X_{t}+u_{t}
$$

where $y_{t}, \pi_{t}$ are vectors ( $\left.24 \times 1\right)$ of current observations of the logarithm of per capita GDP and of the rate of inflation, respectively, for the 24 member countries of the OECD, $\mathbf{X}_{\mathbf{t}}$ is a vector of additional regressors, suggested by growth theory and $\mathbf{A}$ is a vector $(24 \times 1)$ of constants. $\mathbf{C}(\mathbf{L}), \mathbf{D}(\mathbf{L})$ and $\mathbf{G}(\mathbf{L})$ are matrices of order $(24 \times 24)$ in which the elements outside the main diagonal are zero and the element within the main diagonal is a lagged polynomial of order $\mathbf{p}$ such as (for $\mathbf{C}(\mathbf{L})$, for example):

$$
c_{1} L+c_{2} L^{2}+c_{3} L^{3}+\ldots+c_{p} L^{p}
$$

The rejection of the null hypothesis that the $\mathbf{d}_{\mathbf{j}}$ 's are zero indicates that current inflation helps to reduce the mean-squared error in the prediction of per capita income and, therefore, that $\pi$ causes $\mathbf{y}$ in the Granger sense. Likewise, the causality from the growth rate to inflation is tested through the joint significance of $\left\{\mathbf{e}_{1}, \ldots \mathbf{e}_{\mathrm{p}}\right\}$ in:

$$
\pi_{t}=B+E(L) \Delta y_{t}+F(L) \pi_{t}+H(L) X_{t}+\varepsilon_{t}
$$

where $\mathbf{E}(L), F(L)$ and $\mathbf{H}(L)$ are matrices of a structure similar to $\mathbf{C}(L)$ and $B$ is a

${ }^{25}$ Testing the causality from the rate of inflation to the growth rate only entails adding a linear restriction on the coefficients in $\mathbf{C}(\mathbf{L})$, and writting per capita income in first differences. The results of the causality tests to the growth rate are quite similar to those of the causality tests to the level of per capita income and will not be reported here to save space. 
vector $(24 \times 1)$ of constants. The rejection of the null hypothesis that the coefficients $\mathbf{e}_{\mathbf{j}}$ are zero indicates that $\Delta \mathbf{y}$ causes $\pi$.

The elements of the matrices $\mathbf{A}$ and $\mathbf{B}$, as well as the coefficients of the lagged polynomials (in $\mathbf{C}(\mathrm{L}), \mathbf{D}(\mathrm{L}), \mathbf{E}(\mathrm{L}), \mathbf{F}(\mathrm{L}), \mathbf{G}(\mathrm{L})$ and $\mathbf{H}(\mathrm{L})$ ), will be assumed to be homogeneous among countries unless expressly stated otherwise. The estimation of [7] and [8] raises several methodological issues ${ }^{26}$, the most important one being the possibility that some variables are non-stationary, in which case exclusion tests do not have a standard distribution. In the case at hand, both per capita income and the rate of inflation are, for most countries in the sanple, nonstationary. There are several ways in which the hypothesis of causality between integrated variables can be tested making use of statistics with asymptotic standard distribution. These procedures basically consist of a re-parametrisation of the model in order to obtain stationary regressors ${ }^{27}$. The method proposed by Dolado and Lütkepohl (1996) does not require a search for possible cointegration vectors which is quite often a hazardous task in panel data models. These authors propose the estimation of a VAR in levels of order $\mathbf{p}+1$. The exclusion test performed on the $\mathbf{p}$ first lags is thus distributed asymptotically as an $\mathbf{F}$, whereby the loss of efficiency by the over-parametrisation of the model is compensated by the test's consistency and simplicity ${ }^{28}$. The application of this method requires knowing the true order, p, of the VAR. In this paper, rather than discussing the structure of the lags in detail, we present results for a sufficiently broad range of lags that ensure the stationarity

${ }^{26}$ Since this section applies annual data relating to the variables of interest for the 24 OECD countries, it departs from the traditional approach in the empirical literature on growth, which avoids using annual information. Nevertheless, an increasing number of studies tend to use raw annual data. Moreover, in the dynamic analysis of causality, models based on time averages can be considered as restricted versions of models that use annual data. As regards the role of individual effects in multi-country regressions, we shall take them into account in this section by considering several specifications in which vectors $\mathbf{A}$ and $\mathbf{B}$ include a different constant for each country $\left(\mathbf{a}_{\mathbf{i}}, \mathbf{b}_{\mathbf{i}}\right)$.

${ }^{27}$ See Sims, Stock and Watson (1990).

${ }^{28}$ For an application of this method, see Andrés, Boscá and Doménech (1996). 
of the residuals.

The exclusion test in [7] has been performed for ten different structures of lags ( $\mathbf{p}$ going from 3 to 12 ) and for five sets of additional regressors $\left(\mathbf{X}_{\mathbf{t}}\right)^{29}$. Thus, the causality from the rate of inflation to the level of per capita income has been tested in 50 specifications. Table 8 summarises the results of these tests, that can be read as follows. In 47 cases; the null hypothesis that the inflation coefficients are jointly non-significant, and hence that inflation does not cause income, can be rejected at the $5 \%$ level. Furthermore, the sum of the lagged coefficients of inflation is negative in all 50 cases. This would imply that higher inflation today anticipates lower income in the future. However, the evidence of a long run effect of inflation upon income is not unequivocal since the sum of the coefficients of the inflation lags is significantly different from zero (at the $10 \%$ level) in just a half of the cases. This is worrisome since a non-significant long run coefficient can be interpreted as if the effect of inflation on growth is not permanent, casting some doubts on the validity of the correlation found in previous sections.

Table 8 indicates in parentheses the number of specifications corresponding to the model with the largest set of additional regressors: individual effects, lagged accumulation rates and several macroeconomic variables. Many authors have studied the relationship between long-term growth and the short-term performance of economies $^{30}$. The main argument on which this relationship rests is that the shocks

29 These five sets are the following: 1) includes neither additional regressors $\left(g_{\mathrm{j}}=0\right)$ nor constant individual effects; 2 ) includes individual constant effects so that $\mathbf{A}$ is a vector of different constants, one for each country; 3 ) incorporates, in addition to individual effects, several other regressors such as a linear trend, the savings ratio, the rate of schooling and the growth rate of the population, all of them contemporaneous; 4 ) as the previous set, but with the first lag (instead of the current) accumulation rates; and 5) as the previous set plus current exports growth and the first lag of money growth, exports growth, public consumption and public deficit as a percentage of GDP.

${ }^{30}$ See Levine and Renelt (1992), Fischer (1993) and Andrés, Doménech and Molinas (1996), among others, for alternative views of the influence of macroeconomic shocks on growth. 
hitting an economy or the way economic policy is conducted influence the agents' accumulation decisions and the way markets operate. Thus, a succession of negative shocks or an inadequately designed fiscal or monetary policy may have effects that go beyond the short term, affecting potential output and sustained growth. If this argument is correct, the causal interpretation of the estimated correlation between inflation and growth could be called into question. The estimated correlation between growth and inflation could be due simply to the fact that inflation approximates the impact of other macroeconomic variables with which it is strongly correlated. Those specifications that include other macroeconomic indicators allow for an analysis of the influence of inflation on growth while isolating it from the effect of other shocks. The numbers in parentheses indicate that after taking into account the effect of fiscal and monetary policy and the export performance, the existence of causality of a negative sign from inflation to economic growth becomes more apparent. The null hypothesis that inflation does not help to improve the prediction of the future growth rate is clearly rejected in all cases. The statistic associated with the sum of the coefficients of the inflation lags is negative in all cases and statistically significant in most of them ${ }^{31}$.

Although the results of these causality tests are not fully conclusive, their importance is enhanced if we compare them with some similar tests relating growth to other variables such as investment in physical and human capital or public spending. Several recent attempts to corroborate the statistical causality from investment in physical capital to growth and income ${ }^{32}$ have concluded that, even though it cannot be rejected that a high rate of current investment could be explained by rapid growth in the past, the existence of causality in the opposite direction is far less conclusive. Blömstrom, Lipsey and Zejan (1996) show that growth always precedes investment, rather than the other way round. A similar result is obtained by

${ }^{31}$ In eight out of ten cases at a $10 \%$ significance level and in six of them at the $5 \%$ level.

32 Correlations which are among the main findings of the empirics of convergence. 
Carrol and Weil (1993) for the OECD sample. Andrés, Boscá and Doménech (1996) also find that investment does not help to improve the prediction of income nor of its growth rate in practically any of the specifications studied. Moreover, when investment appears to cause income, the negative sign makes this result hard to interpret. A similar effect is obtained in relation to other determinants of growth, like the rate of schooling among others. What these authors find is that most of the observed positive correlation among investment and growth (or income) can be attributed to reverse causation. Reasoning on similar grounds, many authors suspect that something of this kind might be behind the correlation among inflation and growth (Kocherlakota (1996)).

Interestingly enough, unlike what happens with investment and schooling, in this case the causality running from income growth to inflation is indeed significant but with a sign that weakens, rather than strengthens, the case for reverse causality. As can be seen in Table 9, causality from growth to inflation is not rejected in any of the 50 specifications analyzed, thus we may conclude that current growth rates help to explain the future course of the inflation rate. The $\mathbf{t}$ statistic of the long-run coefficient is always positive and significantly so (at the 5 per cent significance level) in 90 per cent of the cases ${ }^{33}$. Economic theory proposes several explanations why rapid growth is associated with higher inflation in the more or less immediate future. On the one hand, it could be a movement along a negatively sloped Phillips curve, as prices respond after a period of rapid expansion in demand. Another interpretation is derived from the so-called Balassa-Samuelson effect ${ }^{34}$. According to these authors, rapid economic growth is associated with rapid expansion in the productivity of a country's tradeable goods sector, in turn leading to an appreciation of its currency. Insofar as the nominal exchange rate is not adjusted to produce this appreciation, domestic prices will grow faster. This leading correlation of a positive

${ }^{33}$ Again, the results are even more clear-cut if we focuss in the specifications with the largest set of additional regressors. In all those ten cases, the null hypothesis of non-causality is rejected and the sum of the inflation lags is positive and significant.

${ }^{34}$ Balassa (1964) and Samuelson (1964). 
sign indicates that the risk of a simultaneity downward bias in the estimation of inflation costs is considerable $\mathrm{e}^{35}$. As a result, the contemporaneous correlation in the convergence equations could be regarded as a lower bound of the costs of inflation, which would have to be adjusted upwards in absolute value.

In the light of this evidence, the results presented in this section have an unequivocal interpretation. The current rate of inflation provides relevant information on income prospects in OECD countries. In particular, ceteris paribus, higher inflation never anticipates a higher level of income in the medium and long run. This effect is robust to alternative specifications and, most notably, survives even when accumulation rates and individual effects are included among the set of regressors. Moreover, it can be rejected that this leading correlation between inflation and income is spurious and produced by the coincidence of inflationary tendencies and slow growth in some economies. Therefore, even though the magnitude of the negative effect of inflation might be questioned, the results of this section tell us that inflation does not appear to be neutral in the long run and that in no case does the persistence of inflationary tensions favour rapid economic growth in the future.

\section{Concluding remarks.}

In this paper we have tried to assess the long-run costs of inflation, within an explicit theoretical framework stemming from the growth literature: the convergence equation. Despite its shortcomings, this approach is well-suited to test the robustness of the correlation between growth and inflation in low-inflation economies with reasonably well-working markets, such as the OECD ones during the 1960-1992 period. The specific results are described at length in each section and will not be repeated here. The main finding is that current inflation has never been found to be positively correlated with income per capita over the long run.

${ }^{35}$ Andrés, Hernando and Krüger (1996) show that when observations under fixed exchange rates are excluded from the sample, the size and the significance level of the coefficient of inflation in OECD convergence equations increase substantially. 
In fact, in most, though admittedly not in all, specifications tried we obtained a significant negative correlation between inflation and income growth during rather long periods. This negative correlation survives the presence of additional regressors, such as the investment rate, population growth and schooling rates, and the imposition of the theoretical restrictions implied by the constant returns of technology. What is most remarkable is that the negative coefficient of inflation in growth equations remains significant even after allowing for country-specific timeinvariant effects in the equations. This is striking since, as it is well known in the empirical growth literature, few regressors in convergence equations withstand the explanatory power of country dummies. The analysis of causality gives less clear-cut results, but it is also noteworthy that causality from inflation to growth is always significant and never positive. Again, this result shows up more clearly whenever the influence of country dummies, accumulation rates and the effect of other macroeconomic variables is controlled for.

Inflation not only reduces the level of investment but also the efficiency with which productive factors are used. It has a negative temporary impact upon longterm growth rates, which, in turn, generates a permanent fall of income per capita. Our results suggest that the marginal cost of inflation diminishes with the inflation rate. The estimated benefit of a permanent reduction of inflation by one percentage point depends on the starting level of inflation. Thus, reducing the inflation rate from (say) $20 \%$ to $19 \%$ may increase output by $0.5 \%$ in the long-run. This benefit increases with further reductions in inflation and might be twice as large when inflation reaches a low 5\%. These benefits seem to be lower than others reported in the literature, but some evidence suggests that they might be underestimated since there is a positive causation running from growth to inflation, in particular for economies with fixed exchange rates. It must also be noticed that these estimates are obtained in models displaying a fast convergence rate, so that the present value of the benefits of disinflation might be quite sizeable. Overall, these results indicate that the long-run costs of inflation are non-negligible and that efforts to keep inflation under control will sooner or later pay off in terms of better long-run performance and higher per capita income. 


\section{References.}

Andrés, J., Boscá, E. and Doménech, R. (1996): "Testing the neoclassical growth model: a causality approach", mimeo.

Andrés, J.; Doménech, R. and Molinas, C. (1996): "Macroeconomic performance and convergence in OECD countries", European Economic Review, 40, 16831704.

Andrés, J., Hernando, I. and Krüger, M. (1996): "Growth, inflation and the exchange rate regime", Economics Letters, 53, 61-65.

Balassa, B. (1964): "The purchasing power parity doctrine: a reappraisal", Journal of Political Economy, 72, 584-596.

Barro, R. and Sala-i-Martin, X. (1991): "Convergence across states and regions", Brookings Papers on Economic Activity, 1.

Barro, R. (1995): "Inflation and economic growth". Bank of England Economic Bulletin, 1-11.

Barro, R. (1996): "Determinants of economic growth: a cross-country empirical study". National Bureau of Economic Research, Working paper 5698.

Blömstrom, M., Lipsey, R. and Zejan, M. (1996): "Is fixed investment the key to economic growth?", Quarterly Journal of Economics, 111, 269-276.

Briault, C. (1995): "The costs of inflation", Bank of England Economic Bulletin, 33-45.

Bruno, M. (1993): "Inflation and growth in an integrated approach", NBER Working Paper 4422.

Bullard, J. and Keating, J. (1995): "The long-run relationship between inflation and output in postwar economies", Journal of Monetary Economics, 36, 477-496. 
Burdekin, R., Goodwin, T., Salamun, S. and Willett, T. (1994): "The effects of inflation on economic growth in industrial and developing countries: is there a difference?", Applied Economic Letters, 1, 175-177.

Cardoso, E. and Fishlow, A, (1989): "Latin American economic development: 1950-1980", NBER Working Paper 3161.

Carrol, C. and Weil, D. (1993): "Saving and growth: a reinterpretation", NBER working paper 4470 .

Clark, T.E. (1993):"Cross-country evidence on long run growth and inflation". RWP 93-05. Federal Reserve Bank of Kansas City.

Cozier, B. and Selody, J. (1992): "Inflation and macroeconomic performance: some cross-country evidence", Department of Monetary and Financial Analysis, Bank of Canada.

Dabán, T., Doménech, R. and Molinas, C. (1996): "International and intertemporal comparisons in OCDE countries: a growth sensitivity analysis", Review of Income and Wealth (forthcoming).

De Gregorio, J. (1992a): "Economic Growth in Latin America", Journal of Development Economics, 39, 59-84.

De Gregorio, J. (1992b): "The effects of inflation on economic growth: Lessons from Latin America", European Economic Review, 36, 417-425.

De Gregorio, J. (1993): "Inflation, taxation, and long-run growth", Journal of Monetary Economics, 31, 271-298.

De Gregorio, J. (1996): "Inflation, growth and central banks: theory and evidence". Policy Research Working Paper 1575, The World Bank.

Dolado, J. and Lütkepohl, H. (1996): "Making Wald test work for cointegrated VAR systems", Econometric Review, 15, 369-386. 
Feldstein, M. (1996): "The costs and benefits of going from low inflation to price stability", NBER working paper 5469.

Fischer, S. (1991): "Growth, macroeconomics, and development", NBER Working Paper 3702.

Fischer, S. (1993): "The role of macroeconomic factors in growth", Journal of Monetary Economics, 32, 485-512.

Grier, K., and Tullock, G. (1989): "An empirical analysis of cross-national economic growth, 1951-80", Journal of Monetary Economics, 24(2), 259-276.

Grimes, A. (1991): "The effects of inflation on growth: some international evidence". Weltwirtschaftliches Archiv, 127(4), 631-644.

Gylfason, T. and Herbertsson, T. (1996): "Does inflation matter for growth?", Center for Economic Policy Research, Discussion Paper 1503.

Islam, N. (1995): "Growth empirics: a panel data approach", Quarterly Journal of Economics, 110, 1127-1170.

Jones, L. and Manuelli, R. (1993): "Growth and the effects of inflation", NBER Working Paper 4523.

Judson, R. and Orphanides, A. (1996): "Inflation, volatility and growth", Federal Reserve Board, Washington, Finance and Economics Discussion Series, 96-19.

Knight, M., Loayza, N. and Villanueva, D. (1993): "Testing the neoclassical theory of economic growth: a panel data approach", IMF Staff Papers, 40, 512-541.

Kocherlakota, N. (1996): "Commentary", Federal Reserve Bank of St. Louis Review, May/June, 170-172.

Kormendi, R., and Meguire, P. (1985): "Macroeconomic determinants of growth. Cross-country evidence", Journal of Monetary Economics, 16(2), 141-163. 
Levine, R. and Renelt, D. (1992): "A sensitivity analysis of cross-country growth regressions", American Economic Review, 82, 942-963.

Levine, R. and Zervos, S. (1993): "What have we learned about policy and growth from cross-country regressions?, American Economic Review, 83, 426-430.

Mankiw, N., Romer, D. and Weil D. (1992): "A contribution to the empirics of economic growth", Quarterly Journal of Economics, 107 (May) 407-38.

McCandless, G. and Weber, W. (1995): "Some monetary facts", Federal Reserve Bank of Minneapolis, Ouarterly review, Summer, 2-11.

Motley, B. (1994): "Growth and inflation: A cross-country study", Federal Reserve Bank of San Francisco, Working Paper 94-08.

Orphanides, A. and Solow, R. (1990): "Money, inflation and growth", en B. M. Friedman and F. Hahn (eds.), Handbook of Monetary Economics, vol. I.

Pesaran, M. H. and Smith, R. (1995): "Estimating long-run relationships from dynamic heterogeneous panels", Journal of Econometrics, 68, 79-113.

Pindyck, R. and Solimano, A. (1993): "Economic instability and aggregate investment", NBER working paper 4380 .

Roubini, N. and Sala-i-Martin, X. (1995): "A growth model of inflation, tax evasion and financial repression", Journal of Monetary Economics, 35, pp. 275-301.

Sala-i-Martin, X. (1994): "Cross-sectional regressions and the empirics of economic growth", European Economic Review, 38, 739-747.

Samuelson, P. (1964): "Theoretical notes on trade problems", Review of Economics and Statistics, 46, pp. 145-154.

Sarel, M. (1995): "Nonlinear effects of inflation on economic growth". International Monetary Fund, IMF Staff Papers, 43, 199-214. 
Sims, C., Stock, J. and Watson, M. (1990): "Inference in linear time series models with some unit roots", Econometrica, 58, 113-44.

Smyth, D. (1994): "Inflation and growth", Journal of Macroeconomics, spring, v. 16, 261-270.

Solow, R. (1956): "A contribution to the theory of economic growth", Quarterly Journal of Economics, 70, 65-94.

Summers, R. and Heston, A. (1991): "The Penn World Table (Mark 5): An expanded set of international comparisons, 1950-1988". Quarterly Journal of Economics, 106(2), 327-368.

Thornton, D. (1996): "The costs and benefits of price stability: An assessment of Howitt's rule", Federal Reserve Bank of St. Louis Review, March/April, 23-38. 


\section{TABLE 1. LINEAR MODELS}

(equation $\left[5^{\prime}\right]$ )

(1)

(2)

(3)

(4)

\begin{tabular}{|c|c|c|c|c|}
\hline Dependent variable & $\Delta y$ & $\Delta \mathrm{y}$ & $y^{*}$ & $\mathrm{y}^{*}$ \\
\hline$\Psi_{0}$ & $\begin{array}{l}0.348 \\
(8.68)\end{array}$ & $\begin{array}{l}-0.241 \\
(1.08)\end{array}$ & $\begin{array}{c}2.314 \\
(25.49)\end{array}$ & $\begin{array}{l}-1.044 \\
(0.96)\end{array}$ \\
\hline$\psi_{1}$ & $\begin{array}{l}-0.010 \\
(3.35)\end{array}$ & $\begin{array}{l}-0.010 \\
(3.08)\end{array}$ & $\begin{array}{l}0.076 \\
(5.22)\end{array}$ & $\begin{array}{c}0.050 \\
(3.41)\end{array}$ \\
\hline$\Psi_{2}$ & $\begin{array}{r}-0.073 \\
(4.40)\end{array}$ & $\begin{array}{l}-0.089 \\
(5.08)\end{array}$ & - & - \\
\hline$\psi_{3}$ & - & $\begin{array}{l}0.045 \\
(1.97)\end{array}$ & - & $\begin{array}{c}0.161 \\
(1.44)\end{array}$ \\
\hline$\Psi_{4}$ & - & $\begin{array}{l}0.030 \\
(1.02)\end{array}$ & - & $\begin{array}{r}0.630 \\
(4.78)\end{array}$ \\
\hline$\psi_{5}$ & - & $\begin{array}{r}-0.123 \\
(1.66)\end{array}$ & - & $\begin{array}{c}-0.052 \\
(0.14)\end{array}$ \\
\hline$\Psi_{6}$ & $\begin{array}{l}-0.002 \\
(2.94)\end{array}$ & $\begin{array}{r}-0.001 \\
(1.73)\end{array}$ & $\begin{array}{r}-0.024 \\
(8.50)\end{array}$ & $\begin{array}{l}-0.014 \\
(4.34)\end{array}$ \\
\hline $\mathrm{R}^{2}$ & 0.30 & 0.36 & 0.37 & 0.52 \\
\hline$\sigma$ & 0.055 & 0.053 & 0.299 & 0.259 \\
\hline
\end{tabular}

Notes:

-Estimation method: instrumental variables. Instruments: constant, trend and first and second order lags of the regressors and second lag of the dependent variable.

-Absolute t-ratios in parentheses. 


\section{TABLE 2. NON-LINEAR MODELS}

(equation [5])
(1)
(2)
(3)
(4)

Dep. variable

$\mathrm{y}^{*}$

$\Delta \mathrm{y}$

$\Delta \mathrm{y}$

$\Delta \mathrm{y}$

$\Omega^{\mathrm{s}}$

$-2.22$

(2.46)

$\Omega^{\mathrm{c}}$

$\begin{array}{lll}-4.09 & -1.97 & -0.19\end{array}$

(2.84) (1.61) (0.13)

$\alpha$

$\begin{array}{llll}0.09 & 0.27 & 0.23 & 0.35\end{array}$

(1.31)

(2.87) (2.56)

(3.45)

$\gamma$

0.31

0.27

0.21

0.11

(6.30)

(3.18)

(2.54)

(1.13)

$\phi_{\mathrm{SS}}$

0.051

(3.35)

$\phi_{\mathrm{c}}$

$\begin{array}{lll}-0.09 & -0.05 & -0.05 \\ (2.57) & (1.79) & (1.91)\end{array}$

$\phi$

(2.57) (1.79) (1.91)

$\mu_{1}$

$-0.013$

$-0.011$

(2.10)

$(4.00)$

(2.03)

$-0.22$

$$
-
$$

0.027

$-0.025$

(2.38)

$\lambda$

$\mathrm{R}_{\mathrm{ss}}{ }^{2}$

0.50

$\mathrm{R}_{\mathrm{C}}{ }^{2}$

0.266

$\begin{array}{lll}0.37 & 0.39 & 0.27\end{array}$

$\sigma_{\mathrm{ss}}$

$\begin{array}{lll}0.053 & 0.050 & 0.057\end{array}$

$\sigma_{\mathrm{c}}$

$\begin{array}{lll}- & 0.053 \quad 0.050\end{array}$

Notes:

-Estimation method: see notes in Table 1.

-Absolute t-ratios in parentheses. 


\section{TABLE 3. CONVERGENCE EQUATION WITH INDIVIDUAL EFFECTS}

(equation [ $\left.5^{\prime}\right]$ )

Dependent variable $\Delta y$

\begin{tabular}{|c|c|c|c|c|c|}
\hline & (1) & (2) & (3) & (4) & (5) \\
\hline$\psi_{0}$ & $\begin{array}{c}-0.26 \\
(1.22)\end{array}$ & $\begin{array}{l}1.54 \\
(2.03)\end{array}$ & $\begin{array}{c}1.18 \\
(6.44)\end{array}$ & $\begin{array}{c}1.24 \\
(2.95)\end{array}$ & $\begin{array}{l}1.07 \\
(3.22)\end{array}$ \\
\hline$\psi_{1}$ & $\begin{array}{c}-0.01 \\
(2.96)\end{array}$ & $\begin{array}{c}0.04 \\
(3.16)\end{array}$ & $\begin{array}{c}0.03 \\
(3.26)\end{array}$ & $\begin{array}{c}0.02 \\
(3.04)\end{array}$ & $\begin{array}{c}0.02 \\
(3.26)\end{array}$ \\
\hline$\psi_{2}$ & $\begin{array}{l}-0.08 \\
(5.15)\end{array}$ & $\begin{array}{l}-0.65 \\
(4.70)\end{array}$ & $\begin{array}{l}-0.48 \\
(5.44)\end{array}$ & $\begin{array}{l}-0.43 \\
(5.45)\end{array}$ & $\begin{array}{l}-0.40 \\
(6.99)\end{array}$ \\
\hline$\psi_{3}$ & $\begin{array}{c}0.05 \\
(2.34)\end{array}$ & $\begin{array}{l}-0.16 \\
(1.54)\end{array}$ & - & $\begin{array}{l}-0.03 \\
(0.84)\end{array}$ & $\begin{array}{l}-0.04 \\
(1.24)\end{array}$ \\
\hline$\psi_{4}$ & -- & $\begin{array}{r}-0.019 \\
(0.28)\end{array}$ & - & $\begin{array}{c}-0.010 \\
(0.25)\end{array}$ & $\begin{array}{l}-0.02 \\
(0.70)\end{array}$ \\
\hline$\psi_{5}$ & $\begin{array}{l}-0.16 \\
(2.34)\end{array}$ & $\begin{array}{l}-0.21 \\
(0.98)\end{array}$ & - & $\begin{array}{r}-0.007 \\
(0.07)\end{array}$ & $\begin{array}{l}-0.007 \\
(0.11)\end{array}$ \\
\hline$\psi_{6}$ & $\begin{array}{l}-0.001 \\
(1.90)\end{array}$ & $\begin{array}{l}-0.001 \\
(1.16)\end{array}$ & $\begin{array}{l}-0.002 \\
(2.29)\end{array}$ & $\begin{array}{c}-0.002 \\
(2.47)\end{array}$ & $\begin{array}{c}-0.003 \\
(3.99)\end{array}$ \\
\hline $\mathrm{R}^{2}$ & 0.36 & 0.35 & 0.50 & 0.48 & 0.48 \\
\hline$\sigma$ & 0.053 & 0.054 & 0.047 & 0.048 & 0.048 \\
\hline$\psi_{6}(\mathrm{LI})$ & & $\begin{array}{l}-0.008 \\
(2.01)\end{array}$ & & $\begin{array}{l}-0.011 \\
(5.18)\end{array}$ & \\
\hline$\psi_{6}(\mathrm{HI})$ & & $\begin{array}{c}-0.001 \\
(0.84)\end{array}$ & & $\begin{array}{l}-0.001 \\
(0.87)\end{array}$ & \\
\hline$\psi_{6}(\mathrm{HI}-\mathrm{ICL})$ & & $\begin{array}{c}-0.002 \\
(1.83)\end{array}$ & & $\begin{array}{r}-0.002 \\
(1.88)\end{array}$ & \\
\hline
\end{tabular}

NOTES:

-HI: sample of 6 countries with the inflation rate above the OECD average; LI: OECD excluding HI countries; HI-ICL: as HI, excluding Iceland.

-Estimation method col. (1): random effects (instrumental variables);

Instruments: first and second lags of the regressors.

-Estimation method cols. (2)-(5): Country-dummies instrumental variables;

Instruments: as in Table 1 plus country dummies and inflation variability.

-Dummy variables included:

-Columns (2) and (3): one for each country except Australia.

-Column (4): one for each of the following countries: Canada, Switzerland, Germany, Spain, United Kingdom, Greece, Ireland, Iceland, Luxembourg, New Zealand, Portugal, Turkey and United States. -Column (5), one for each of the following countries: Spain, Greece and Turkey and one for each of the following country groups: Ireland and Portugal; Canada and Germany; Switzerland, Luxembourg, Iceland an United States; and New Zealand and United Kingdom. 
TABLE 4. LINEARITY OF THE INFLATION EFFECT

\section{Elasticities of income with respect to inflation in estimates of the linear version of the convergence equation}

A. Whole sample estimates with specific inflation coefficients

$\begin{array}{lc}\text { Low inflation }^{(1)} & -0.091 \\ & (2.33) \\ \text { Medium inflation }^{(1)} & -0.061 \\ & (2.58) \\ \text { High inflation }^{(1)} & -0.066 \\ & (4.23)\end{array}$

B. Sub-sample estimates

Low inflation ${ }^{(2)} \quad-0.052$

$\begin{array}{ll}\text { High inflation }^{(2)} & -0.034 \\ & (2.15) \\ \text { Very low inflation }^{(3)} & -0.036 \\ & (1.82) \\ \text { Very high inflation }^{(3)} & -0.046 \\ & (1.61)\end{array}$

NOTES:

-Estimation method: see notes in Table 2.

-Absolute t-ratios in parentheses.

-(1) Low inflation: observations with inflation lower than 6\%; Medium inflation: observations with inflation between $6 \%$ and $12 \%$; High inflation: observations with inflation greater than $12 \%$.

-(2) Low inflation: countries with average inflation lower than the median; High inflation: countries with average inflation greater than the median.

-(3) Very low inflation: eight countries with the lowest inflation. Very high inflation: eight countries with the highest inflation. 
TABLE 5: LONG RUN EFFECT OF INFLATION ON PER CAPITA INCOME ${ }^{(1)}$.

\begin{tabular}{lcccc} 
MODEL $^{(2)}$ & \multicolumn{2}{c}{ OECD } & \multicolumn{2}{c}{ OECD (Ex. Iceland) } \\
& Low $^{(3)} \pi$ & $\operatorname{High}^{(4)} \pi$ & Low $^{(3)} \pi$ & High $^{(4)} \pi$ \\
$\pi, \pi^{2}$ & $0.80 \%$ & $0.40 \%$ & $1.10 \%$ & $0.60 \%$ \\
$\pi /(1+\pi)$ & $0.45 \%$ & $0.30 \%$ & $0.70 \%$ & $0.50 \%$ \\
$\log (\pi)$ & $2.00 \%$ & $0.30 \%$ & $2.20 \%$ & $0.40 \%$ \\
$\pi$ & $0.75 \%$ & $0.75 \%$ & $0.75 \%$ & $0.75 \%$
\end{tabular}

NOTES:

-(1) The long run effect is calculated as the coefficient of inflation divided by the coefficient on initial income in the convergence equation augmented with country dummies.

-(2) The variables in the first column indicate the way in which inflation enters in each model.

-(3) Low $\pi$ : reducing inflation from $4 \%$ to $3 \%$

-(4) High $\pi$ : reducing inflation from $20 \%$ to $19 \%$

-Initial GDP non instrumented.

\section{TABLE 6: PER CAPITA INCOME GAIN FROM REDUCING} INFLATION: STEADY-STATE AND PRESENT VALUE.

$\begin{array}{lcc} & \text { Basic model } & \text { Country effects } \\ \text { Steady-state per capita income gain } & 2.5 \% & 0.75 \% \\ \lambda & 2.5 \% & 13 \% \\ \text { Half-life per capita income gain } & 1.25 \% & 0.375 \% \\ \text { Present value: discount rate 4\% (1) } & (30 \text { years }) & (7 \text { years }) \\ \text { Present value: discount rate 5\% (1) } & 0.32 \% & 0.29 \% \\ \end{array}$

NOTE:

(1) Discounted present value of half-life gain (expressed in percentage points of steady state per capita income) 
TABLE 7. INFLATION EFFECT FOR DIFFERENT PERIODS

Coefficients of inflation in a linear version of the convergence equation ${ }^{(1)}$

A. Demand shocks predominance period ${ }^{(2)}$

OLS

$(2.33)$

$\mathrm{IV}^{(3)}$

$-0.003$

$(2.52)$

B. Supply shocks predoninance period ${ }^{(2)}$

$\begin{array}{ll}\text { OLS } & -0.004 \\ & (3.85) \\ \text { IV }^{(3)} & -0.003 \\ & (2.14)\end{array}$

\section{NOTES:}

-(1) Equation [5'] excluding the trend.

-(2) Demand shocks predominance period: 1961-1972 and 1989-1992. Supply shocks predominance period: $1973-1988$.

-(3) Instruments: constant, first and second order lags of the regressors and second lag of the dependent variable.

-Absolute t-ratios in parentheses. 
TABLE 8: CAUSALITY FROM INFLATION TO PER CAPITA INCOME ${ }^{(1)}$ NEGATIVE ${ }^{(2)}$ POSITIVE $^{(2)}$

\begin{tabular}{|c|c|c|c|c|}
\hline \multirow{3}{*}{$\begin{array}{l}\text { Causality }{ }^{(3)} \\
\text { Non-causality }{ }^{(3)}\end{array}$} & $\begin{array}{l}\text { Significant at } \\
\text { the } 5 \% \text { level }\end{array}$ & $\begin{array}{l}\text { Significant at a level } \\
\text { between } 5 \% \text { and } 10 \%\end{array}$ & $\begin{array}{l}\text { Non- } \\
\text { significant }\end{array}$ & \\
\hline & $15(6)$ & $10(2)$ & $22(2)$ & -- \\
\hline & - & - & $3(0)$ & -- \\
\hline
\end{tabular}

Notes:

-(1) Each cell represents the number of specifications in that case. In parentheses, the number of specifications corresponding to the model with individual effects, lagged accumulation rates and lagged macroeconomic indicators.

-(2) Sign of the t-statistic for the sum of the coefficients of the inflation lags.

-(3) Causality (non-causality): The null hypothesis that the inflation coefficients are jointly non-significant is (is not) rejected at the $5 \%$ level.

TABLE 9: CAUSALITY FROM GROWTH TO INFLATION ${ }^{(1)}$ NEGATIVE $^{(2)} \quad$ POSITIVE $^{(2)}$

\begin{tabular}{|c|c|c|c|c|}
\hline \multirow{3}{*}{$\begin{array}{l}\text { Causality }^{(3)} \\
\text { Non-causality }\end{array}$} & & $\begin{array}{l}\text { Non- } \\
\text { significant }\end{array}$ & $\begin{array}{l}\text { Significant at a level } \\
\text { between } 5 \% \text { and } 10 \%\end{array}$ & $\begin{array}{c}\text { Significant at } \\
5 \% \text { level }\end{array}$ \\
\hline & -- & $3(0)$ & $2(0)$ & $45(10)$ \\
\hline & -- & -- & -- & -- \\
\hline
\end{tabular}

Notes: See Table 8. 


\section{CHART 1: SENSITIVITY OF THE INFLATION COEFFICIENT (1) TO THE SAMPLE DEFINITION}

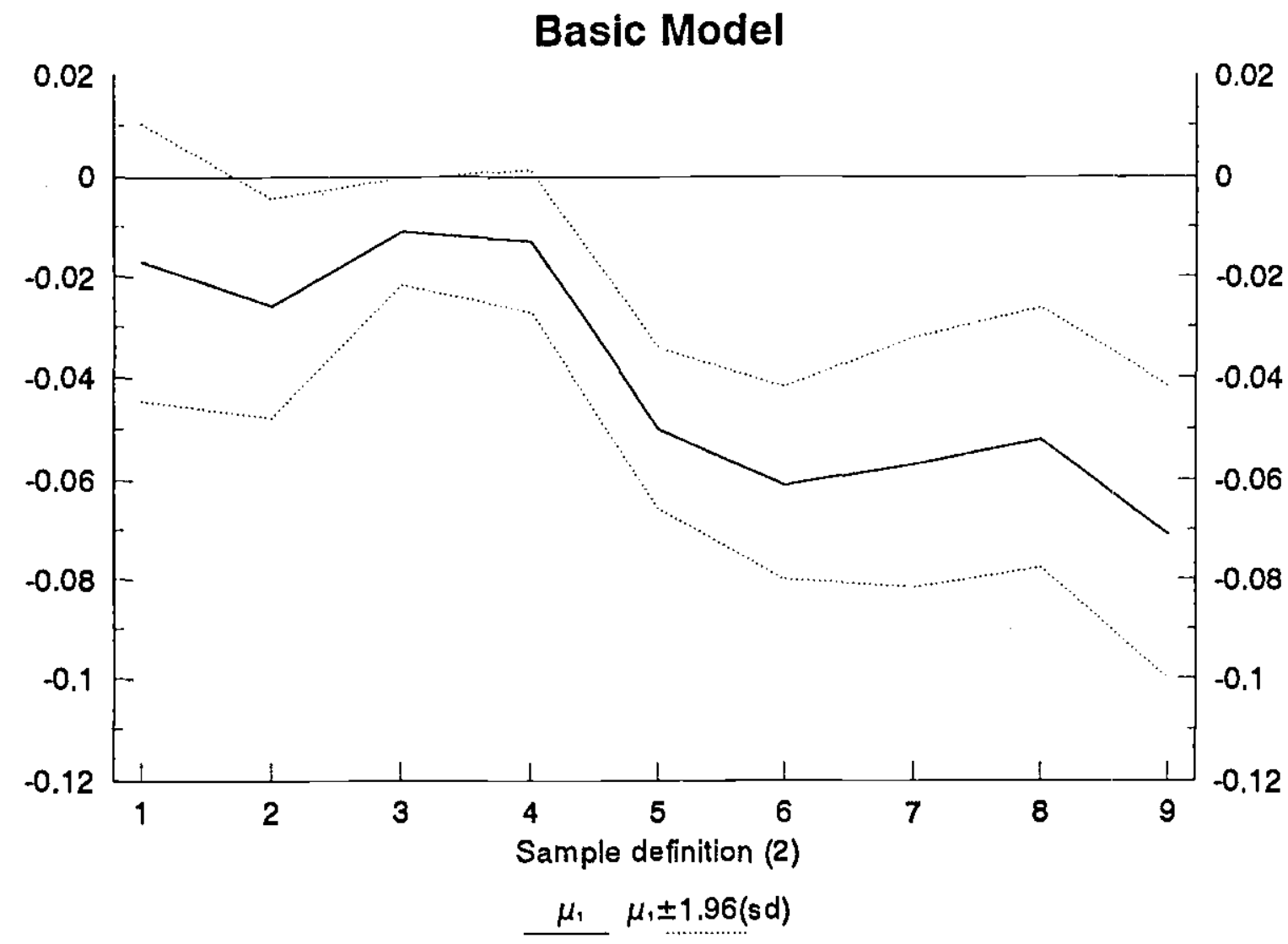

Notes:

(1) The chart depicts the estimated coefficient $\left(\mu_{1}\right)$ for inflation in model [5] as well as the $95 \%$ confidence intervals ( \pm 1.96 standard deviation band) for different sample definitions.

(2) Sample definition:

1.- High inflation countries (above OECD average)

2.- High inflation countries (excluding lceland)

3.- OECD

4.- OECD excluding Turkey

5.- OECD excluding Turkey and lceland

6.- OECD excluding Turkey, lceland and Portugal

7.- OECD excluding Turkey, Iceland, Portugal and Greece

8.- OECD excluding Turkey, Iceland, Portugal, Greece and Spain

9.- Low inflation countries (below OECD average) 
CHART 2: SENSITIVITY OF THE INFLATION COEFFICIENT (1) TO THE SAMPLE DEFINITION

Country dummies (restricted model)

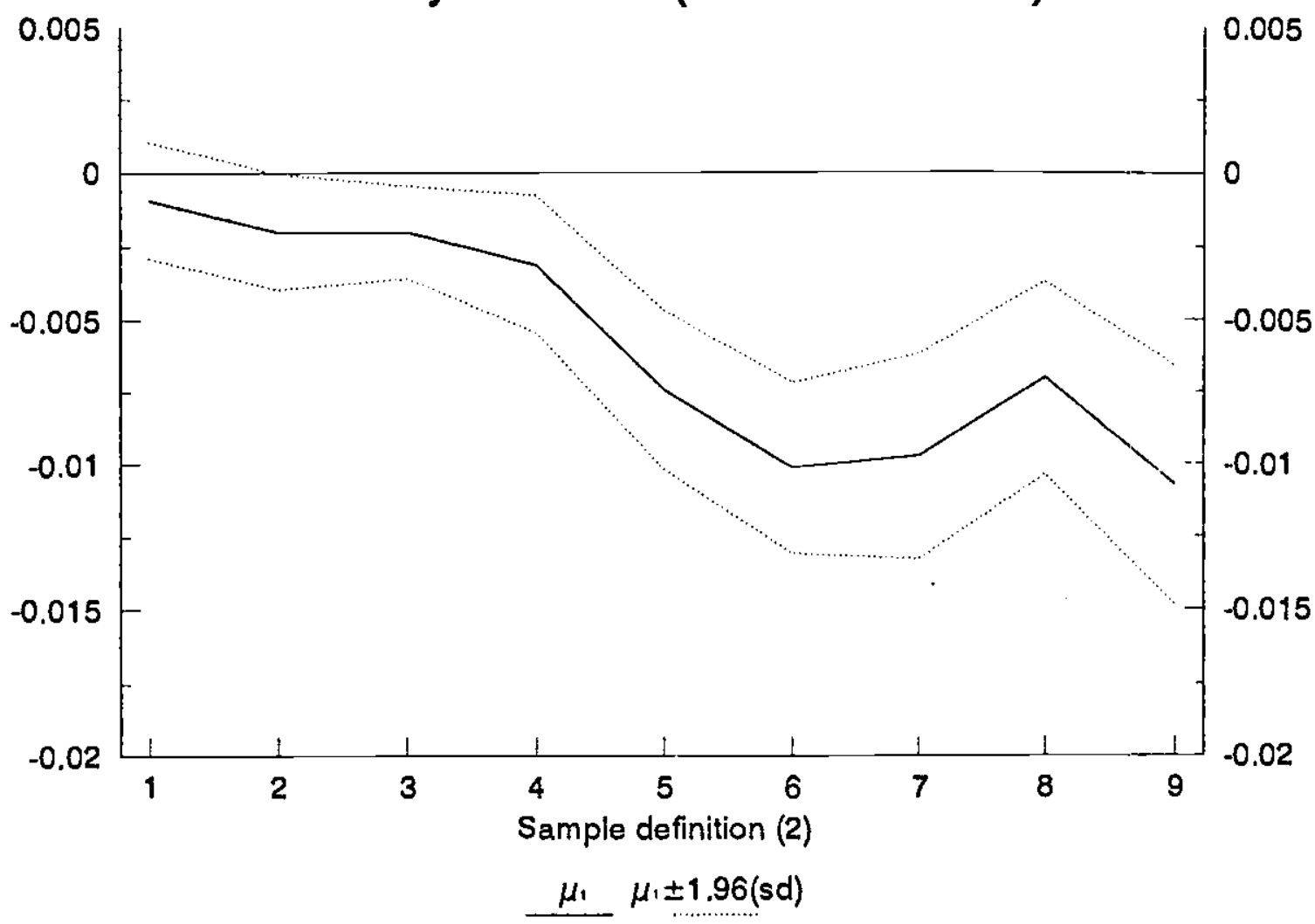

Notes:

(1) The chart depicts the estimated coefficient $\left(\mu_{1}\right)$ for inflation in model [5] as well as the $95 \%$ confidence intervals ( \pm 1.96 standard deviation band) for different sample definitions.

(2) Sample definition:

1.- High inflation countries (above OECD average)

2.- High inflation countries (excluding lceland)

3.- OECD

4.- OECD excluding Turkey

5.- OECD excluding Turkey and lceland

6.- OECD excluding Turkey, lceland and Portugal

7.- OECD excluding Turkey, Iceland, Portugal and Greece

8.- OECD excluding Turkey, lceland, Portugal, Greece and Spain

9.- Low inflation countries (below OECD average) 